\title{
MUJER Y MATERNIDAD: ANTIGUOS TROPIEZOS Y NUEVOS MALESTARES
}

\author{
María del Carmen Rodríguez-Rendo \\ Psicoterapeuta psicoanalítica didacta de la Federación \\ Española de Asociaciones de Psicoterapeutas
}

Antes de leer en voz alta y delante de muchas criaturas (...), lo primero que hay que hacer es pedir ayuda al duende, que es la única manera de que todos se enteren sin ayuda de inteligencia ni aparato crítico...

Estas palabras de Lorca me animan a invitaros a compartir unas reflexiones sobre un tema cuyos matices hacen que "con la misma velocidad que la voz" queden "trabados tupidamente" los sentimientos y las ideasdando lugar fácil al malentendido a veces, y al prejuicio otras. Por eso pido "la ayuda cordial del duende".

\section{A modo de introducción}

Este texto contiene un breve relato clínico. El motivo de incluirlo ha sido aprovecharlo como metáfora sobre la que apoyar algunas reflexiones sobre las dificultades y tropiezos de la mujer en relación con el lugar que ha ocupado dentro del discurso social antes y ahora.

El eje del texto pasa por un intento de recuperar algunos aspectos del discurso de la histeria, intentando apartarlo de la categoría despreciativa que ha llegado a tener (en frases tales como "no te pongas histérica"). Recuperarlo como subversivo frente al discurso de un Amo representado en los imperativos socio-culturales; con la intención de preguntarnos hasta qué punto lo que en su día fue un giro subversivo se ha vuelto en contra de la mujer empujándola, bajo otros paradigmas, a retornar al lugar de ser todo para el otro. 


\section{Las mujeres de ayer y de hoy}

Hablar de la mujer y de sus tropiezos anima a sumergirse en los ecos y vaivenes que han atravesado en todos los tiempos las vidas de las mujeres.

Octavio Paz decía en 1977 refiriéndose a la escritura: "La forma es una máscara que no oculta, sino que revela. Pero lo que revela es una interrogación". Creo que esta frase podría ser una buena síntesis del malestar de algunas mujeres de hoy, que impulsadas por su deseo se exigen ser "una mujer $10 "$.

La máscara, como decía O. Paz, no oculta sino que revela una pregunta por el deseo de la mujer como sujeto: por un lado sujetada a los antiguos emblemas culturales, y por otro, sujetada a las servidumbres imaginarias en las que se llegan a ver sumergidas por los cambios socio-culturales, donde pareciera que el amo ha cambiado de discurso pero no abandona sus mensajes de seducción en las que se enreda, a veces con poca resistencia, la ingenuidad inteligente de ciertas mujeres.

Tengo la impresión de que la vida hoy es "más-cara" porque las preguntas se han ido ahogando en el temor a perder el tiempo, o en el temor a encontrarse con algo que se cree que no se puede cambiar, y así se enmascara el vacío, el agujero, la falta. La actualidad muestra una cierta depreciación del sujeto y por ende del ser, del ser mujer.

Cuando alguna mujer queda atrapada en la imposibilidad de mirar lo que falta como condición de humanidad, algunas, sólo algunas, prefieren rellenar ese agujero que garantiza la misma imperfección que las humaniza. Se mueven sin descanso y ciegamente hacia la conquista de la supuesta perfección del tenerlo todo. Así obturan una trayectoria que les impide disfrutar de esa ausencia capaz de alojar los sueños, y pagan un elevado precio (para suplantar su ser femenino) en nombre de lo bello, lo perfecto, lo más caro, lo mejor, en última instancia: "lo más". 
A continuación voy a introducir un breve relato clínico con la intención de ilustrar esta cuestión.

\section{Relato clínico: "Un hijo de mi sangre"}

Elvira tiene 45 años. Pide una entrevista y acude a ella 40 minutos más tarde. Cuando la recibo, le propongo otra cita; ella se molesta y dice en tono airado: “¿Qué rigidez! Es tarde, pero jamás hubiese imaginado que no me iba a recibir".

En la segunda entrevista me dice que ella "está muy bien, que en realidad no tiene ningún problema, que su vida profesional está llena de éxitos, y su relación de pareja es maravillosa." Tener un hijo en este momento es lo único importante a lo que aspira y se arrepiente de haber abortado a los 22 años porque ahora quiere quedarse embarazada y no lo consigue. No entiende por qué, ya que ha consultado a los mejores especialistas y le han asegurado que está estupenda, que representa 10 años menos de los que tiene y no saben dar cuenta de su "supuesta esterilidad". Su marido también se ha hecho las pruebas y tampoco tiene ningún problema físico.

Al cabo de algunas entrevistas le pregunto si ha contemplado la posibilidad de adoptar un niño. Responde indignada: "Soy muy joven para pensar en eso y además quiero un hijo de mi sangre que complete mi bienestar."

Paralelamente al trabajo analítico pide consulta en "la mejor clínica que se ocupa de la fertilización in vitro". Unos meses después de iniciado el tratamiento llega el día de la laparoscopia. La ingresan y en el momento de entrar en el quirófano tiene una crisis de pánico que obliga al médico a interrumpir todo el proceso.

Aunque el discurso de la paciente ponía de manifiesto su intolerancia al dolor físico, ella consideraba que no iba a dejar de intentar quedarse emba- 
razada para tener "un hijo de su sangre".

Un año después su ginecólogo la llama por teléfono para avisarle que acaba de nacer una niña que va a ser entregada en adopción. Ella y su marido aceptan de inmediato. Cumplidos los trámites pertinentes se llevan a la niña y Elvira dice sentirse feliz.

La niña es "hermosa" y la única sombra que entorpece esta felicidad es el temor de llevarla al parque: "Podría venir la madre biológica y robármela".

Un tiempo después la paciente decide que su trabajo conmigo ha concluido. Que no hay razón para continuar ya que había "conseguido lo que quería”.

Pasan cuatro años y vuelve a llamarme, en esta ocasión para pedirme una entrevista para ella y su marido pues, según dice, "querrían preguntarme algo".

En la entrevista formulan su pregunta: "Díganos, ¿hace falta que la niña sepa que es adoptada? Va a cumplir 5 años, nunca hemos tocado el tema y plantear esto ahora nos parece provocarle un conflicto". Elvira agrega: "Nnunca nos ha dado problemas, es la mejor de su clase, va a un colegio bilingüe super bueno, es carísimo, y tenemos miedo que por decir la verdad todo se estropee, temo que deje de querernos, que quiera buscar a su madre biológica; de todas maneras yo he guardado en una cajita todos los datos de su nacimiento donde figura el nombre de su madre biológica. Hace unos días me dijo: 'Mamá ¿cómo era cuando yo estaba en tu tripita?"”.

La entrevista termina con una manifiesta frustración expresada por el marido refiriéndose al sin sentido de haber venido a la consulta. Cuando se van, el padre me increpa: "Pero vamos a ver, ¿acaso usted tiene hijos? Supongo que no, ya que no es capaz de responder a nuestra pregunta". Les indico 
que deberíamos seguir hablando del tema en otra entrevista. Ambos responden: "No hace falta".

Al cabo de 2 años me entero a través de la colega que me había derivado a la paciente que habían emigrado a otro país fuera de Europa. Hasta aquí el relato de lo sucedido.

\section{El deseo de un hijo}

El deseo de un hijo confronta a toda mujer con una puesta a prueba de su narcisismo. Será en la dimensión de la castración donde se vehiculizará la posibilidad de un hijo, ya que para los dos sexos, castración quiere decir renuncia, rechazo de un goce para que se abran las puertas de un proyecto con el otro.

En muchas ocasiones lo que se expresa como deseo de hijo oculta el deseo de algo más: eso que aún no se tiene y las otras tienen. Es decir, eso que venga a colmar, a llenar el hueco cuando no es soportable que algo falte.

Se posterga la pregunta por el ser del otro, facilitadora para construir un proyecto. Se desafía al tiempo cuando el cuerpo se anuncia como tiempo pasado. Se sortea la soledad particular para eludir el dolor de admitir que no se puede todo, y se hace gala de un narcisismo que a veces ronda los extremos.

Para Freud el origen de la curiosidad anidaba en ese genital femenino del que le hablaban sus pacientes. Y allí se daban cita para él el horror, la perplejidad angustiada, un duradero enigma, y fundamentalmente un deseo de saber. 
Como dice J.C. Indart

La vagina no es una enunciación sin enunciado, ni un decir sin dicho. Disfrazarla de Esfinge ya es dar lugar al miedo y a las más sublimes creaciones fetichísticas de mejor o peor gusto.

Personalmente, no creo en el supuesto del "enigma femenino", sino en el enigma de un sujeto divido y por eso enigmático, portador de una cicatriz incurable independientemente de su anatomía.

El enigma es el de un ser que se halla eclipsado por la objetivización del sujeto, fenómeno desafortunadamente muy extendido entre humanos y entre los paisajes que los humanos habitamos. Nos ha ido rodeando una "arquitectura extrahumana" y un "ritmo furioso", ya que este sujeto del occidente capitalista suele mostrarse dispuesto y diligente cuando de obturar la castración se trata, rindiéndose ante las diferentes formas de los cultos al falo, como lo son algunas formas de saber, de éxito y de poder.

Los tipos de vida en las grandes ciudades no facilitan el encuentro, "hay que quedar" y con la agenda a la vista. Las mismas ciudades eyectan a la gente a las ciudades dormitorio. Y este movimiento de eyección se filtra en todo el tejido relacional. "Geometría y angustia", decía Lorca. Esclavitud dolorosa entre el humano y la máquina.

La velocidad contamina las relaciones con los otros y anula la dimensión histórica del sujeto. La dimensión diacrónica molesta, y la inmediatez por la que suspira el sujeto postmoderno ha llevado a la hiperinflación del ahora. En medio del reino del Dios de lo instantáneo tener tiempo ha pasado a ser un bien escaso.

¿Cómo tener hijos si comprar el tiempo es tan caro? ¿Cómo tener hijos cuando el vínculo con el otro está infectado por la velocidad y la inmediatez? 
Un hijo nace y pertenece a una estirpe, luego ¿cómo preservar la filiación, si la perspectiva histórica ha caducado?

Los valores, las ideas, que eran los referentes han cambiado. El peso moral del discurso social forma parte del malestar de la mujer. Además de tener un cuerpo, necesita tiempo, historia, capacidad de espera y ser atea, para que los Dioses del Ahora no la emboben y no entrar en el juego del reproche porque su talla ya no es la 38 .

Para Freud estaba claro que eso de ser hombre o ser mujer era un punto de llegada, un universo a conquistar y no sólo algo dado por un hecho biológico. Freud se preguntaba durante una sesión de análisis con Marie Bonaparte: ¿Qué quiere la mujer? Reconociendo que no había podido responderse.

El inconsciente como "sede de los deseos" ¿acaso ¿tiene sexo? ¿Tiene género? Como dice Mariam Alizade: “La pregunta ‘¿qué quiere una mujer?', ¿no se habrá ido conviertiendo en una pregunta-síntoma de Freud y de la cultura?".

Si haber dado a luz asegura que un cuerpo ha salido de otro cuerpo, la maternidad como hecho psíquico es un lugar que se construye, y no rápidamente, y no sin tropiezos.

El cuerpo tiene una capacidad de adaptación más rápida que el psiquismo. En 9 meses de embarazo se transforma. Ella pierde la cintura y con la cintura pierde un lugar psíquico para acceder a otro. En el nuevo lugar será una inmigrante desorientada. Estará acompañada por el equipaje de su historia familiar pero con pocos referentes.

Antes, cuando una mujer tenía un hijo, se podía quedar en su casa cuidando del niño; hoy, en muchos casos, tiene que contratar a alguien para que la sustituya. Es decir, el encuentro con el hijo, con otro, no está favorecido. Por eso celebro que sigan existiendo hombres y mujeres dispuestos a luchar 
porque se produzca el encuentro, no el encontronazo. Estar juntos frente a un real que separa, distancia, extravía y aísla.

Cuando se observa el mecanismo de la sociedad global, la singularidad del sujeto pierde los bordes, y los perfiles se borran. Hoy el estar ha sido privilegiado (de igual manera que lo ha sido el cuerpo, la juventud, el prestigio social, el dinero etc.) bajo un imperativo social que impone el goce de los que mandan: los medios, la publicidad, en última instancia la ética narcisista que desasiste al sujeto, que lo aleja de los otros mientras los que mandan responden a la necesidad de mostrar las supuestas coordenadas del estado bienestar: sostener una imagen que es "la que está bien vista" y que es la que vende en muchos ámbitos de la vida.

El ser ha caído en desuso dando paso al prestigio de la lógica del tener. Sin embargo el problema pareciera estar en que los humanos se relacionan a pesar de sí mismos. El saludo entre dos vecinos, “hola”, o ¿“cómo está?”, denuncia que se ha producido un encuentro. Es decir, los humanos establecemos vínculos porque hablamos, establecemos lazos.

Desde el principio los humanos hemos creado un lazo con el otro para ser, para producir, para crear y lo que nos cuenta la historia es que ese lazo social fundamental, formado por al menos dos, consistía en que uno mandaba y otro obedecía, al mismo tiempo que se clamaba al cielo por la existencia de un tercero que pusiera algo de orden a tanto impulso incontrolable.

El tercero ignorado pero existente de otros tiempos ahora también se postula en decadencia. La función paterna se asoma desfalleciente en las problemáticas de niños y adolescentes que llegan a nuestras consultas. Si antes los campos del saber se postulaban en la tendencia a "matar al padre" por la sobreabundancia de patriarcado, hoy se preguntan dónde hay un padre. Y si es difícil encontrarlo no puede ser fácil tener hijos. Que esto no sea agradable no cambia las cosas. 
Los que piensan se inquietan, se angustian, y varios entran en conflicto consigo mismos. Hay otros que no piensan, obturan sus preguntas, temen que algo se mueva del sitio en que fue colocado en nombre de lo fácil o de lo cómodo. El resultado: obedecer.

Si toca mandar, mandan; si toca obedecer, obedecen.

Entonces hay un lazo social instituido que más que un lazo es un problema, lo que los psicoanalistas llamamos síntoma. El lazo problemático por excelencia, del que no voy a hablar pero por el que debo pasar, es: ¿cómo se relacionan las mujeres con los hombres?

En algunos casos la pasividad o la complicidad hace que se confundan en una relación imaginaria con el otro, donde la mujer se transforma en el peor enemigo de sí misma.

Durante siglos, en el sistema patriarcal, ha resultado normal que los hombres preguntaran a las mujeres: “¿Qué tenemos para comer?”. Y a partir de la satisfacción del estómago, tanto el resto del cuerpo de los otros familiares como el ocuparse de todo lo esté ligado al hogar ha caído del lado de la tarea de las mujeres. Y ha sido normal que la mujer respondiera, preparase la comida y la sirviera. Si se preguntaba a una mujer: “¿Profesión?”, ella respondía en muchos casos: "Mis labores”. Y ¿cuáles eran sus labores?: servir, callar, sucumbir al deseo de ser todo y lo único para el otro.

No habían sucumbido al victimismo sino al secreto encanto de vivir para agradar al otro. Tal vez habían caído en la niebla espesa de comprender lo que no debían, para completarse con quien no era, guiadas por aquella voluntad de gloria, heroica y silenciosa. "No te señales, hija" decían las abuelas.

El supuesto misterio de la mujer se ha ido balanceando entre lo sagrado y lo idealizado de un lado y la omnipotencia o la estupidez del otro. 
La madre fue divinizada, la posición sacrificial se entronizó y el misterioso universo de la mujer devino un inquietante espacio bizarro donde se fueron alojando las especulaciones más oscurantistas.

En otras palabras, la relación habida con la madre, en algunos casos, fue trasladada a la relación con la pareja colocando al compañero en el lugar del hijo; en otros, se ha esperado que el hombre responda a una demanda a la madre y de ahí, en parte, la disparidad que habita las parejas, y de ahí también la dificultad de algunas mujeres para quedarse embarazadas.

Como decía Maud Mannoni, para que exista un hijo tendría que preexistirle un lugar en el psiquismo parental.

Las cosas empezaron a girar en el escenario donde se dilucidan las cuestiones importantes: en la cama. A partir de ahí asistimos a la primera rebelión exitosa contra un amo: la rebelión sexual.

A partir de ahí, lo que llamaron el síntoma histérico triunfa y bienvenido fue. Cuando él la reclamaba, ella empezaba a decir: "No sé”, "Estoy cansada", "Me duele la cabeza", etc. Era verdad que le dolía la cabeza, cómo no iba a dolerle si no sabía cuál era su lugar, ni cómo posicionarse.

Más tarde, la histeria que en un principio era patrimonio de las mujeres, ya que era menester poseer un útero para padecerla, deviene sufrimiento independiente del género.

Podríamos pensar que la histeria fue en su día una buena estrategia para cambiar de lugar pero, como toda máscara, oculta más al propio sujeto para sí que lo que esconde a la mirada de los otros.

Algunas veces la máscara se ha ido transformado en el maquillaje engañoso de un ser que se arriesga a una nueva esclavitud. Es decir, el giro que hizo posible salir de una posición devino, para algunas mujeres, en una encerrona. En el intento, la mujer sale a la calle, exige derechos pero desatiende 
su deseo. La consecuencia, siempre la misma: tejer la propia trampa.

Las diferentes modalidades identificatorias que el discurso social ha ido ofertando señalan nuevos lugares donde alojar el exceso (el goce) pero sin tratarlo. Ese exceso que no se nombra pero que obliga a ciertas mujeres a sostenerse en la mentira de un enigma.

No solamente los tiempos han cambiado sino que el tiempo ha cambiado y en consecuencia la relación subjetiva con el tiempo. La velocidad, además de formar parte de un problema de la economía, se ha convertido en una amenaza tiránica para la vida misma. La velocidad es un medio para llegar a alguna parte y una de las quejas más oídas de las mujeres hoy es: "No llego a todo".

Si a la velocidad le sumamos los lugares de poder, inseparables de la riqueza, ya tenemos "el triángulo de las Bermudas". Velocidad, poder y riqueza forman el escenario postmoderno donde perecen ciertos sueños y muchos buenos propósitos se ahogan.

La lucha por el reconocimiento, la demanda de ser igual que el hombre ha colocado a algunas mujeres en este laberinto actual, lo que Virilio llama "una sociedad de carreras". Ahora ellas también corren y mientras corren se agotan, les duele el cuerpo, prodigioso vehículo de la queja.

Algunas tienen éxito profesional, pero no tienen tiempo para tener un amor, o un hijo, o no saben cómo armonizar la vida familiar y la dedicación a los hijos con la vida laboral. Otras no saben cómo seguir siendo jóvenes y bellas después de los 40 .

Los tratamientos de estética, la fecundación in vitro, se han transformado, en ocasiones, en una lucha impertinente para ocultar que el tiempo pasa, que existe el límite. La promesa totalizante parece haber atrapado a la mujer como objeto porque ella, a pesar de sí misma, se desliza a ese lugar de 
ser todo, ¿para quién? Para la madre. Y aquella antigua envidia al pene apuntada por Freud ha hecho las veces de muralla defensiva creando conflicto y rechazo en el esperado encuentro de la mujer con lo femenino.

Si nada falta donde nada hubo, la falta indispensable para procrear debe ser metáfora de una completud a la que habrá que renunciar.

Cuando la aspiración de ser igual que el hombre virtualmente se coagula, ellas tienen, aún, menos tiempo. Antes se sentían atrapadas en la casa, ahora "el afuera" las llama, las seduce y a velocidad de vértigo. La trampa adquiere una nueva forma.

El reloj biológico marca un límite. Los hombres pueden tener hijos en edades avanzadas. De ahí la interrogación: ¿se han instalado algunas mujeres en ser objetos de ellas mismas?

Decía Lacan que las verdades "hay que rodearlas", yo diría incluso, hacer un quiebro, con tal de aproximarnos a ellas, habiendo admitido que esa es nuestra máxima ambición.

Y hay que rodearlas porque las verdades no son enteras, porque no hay nada entero, ni completo, ni perfecto.

No hay enigma, hay diferencia.

El otro existe, no es reemplazable, ni sustituible.

Y la diferencia está contenida en la relación con el otro, como vocación de la especie.

"Si la relación suprime la diferencia, ya no se trata más de una relación real", decía Badiou. Por eso insisto: no hay enigma hay diferencia.

El supuesto enigma femenino ha estado al servicio de la sustitución fálica como forma de evitar la confrontación con la castración. Podemos pen- 
sar que esto ha contado con el auxilio por parte del discurso social: de la velocidad, el poder y la riqueza que se han instalado con prontitud en el viejo antagonismo entre cultura y vida pulsional. "En términos universales, nuestra cultura se edifica sobre la sofocación de las pulsiones" decía Freud en 1908.

Ahora no todas las pulsiones se dejan sofocar y el goce propone a cada individuo que ceda un fragmento de su patrimonio subjetivo. Es decir, los niños no vienen de Dios, ni los trae la cigüeña, no hay continente negro y si lo hay está en África, pero no en la interioridad de la mujer.

En el cuerpo de la mujer se presentifican la vida y la muerte, la vulnerabilidad y el peligro. Es carne abierta de un cuerpo de hembra, que en el mismo instante del parto se trastoca en una angustia sin nombre, en una verdad sabida a medias sobre lo humano, lo perecedero y lo transitorio.

Dar vida es precipitarse en un acontecimiento en el que la especie se perpetúa, es evocar la infancia y tocar las raíces de la finitud. Dar vida es como haber rozado las aristas la muerte.

\section{NOTA}

Este texto fue leído el 5 de noviembre de 2004 en León, en la Concejalía de la Mujer, formando parte de la presentación de Diván El Terrible; y el 12 de noviembre de 2004 en la Asociación de Estudios Psicoanalíticos de Salamanca. 